\title{
Residence Times in a Hypersaline Creek: Using Salinity as a Tracer
}

\author{
Seyed Taleb Hosseini ${ }^{*}$, Vahid Chegini ${ }^{2}$, Masoud Sadrinasab ${ }^{3}$, Seyed Mostafa \\ Siadatmousavi ${ }^{4}$, Sadegh Yari ${ }^{5}$ \\ ${ }^{1}$ Iranian National Institute for Oceanography and Atmospheric Science, Tehran, Iran; sthosseini@gmail.com \\ ${ }^{2}$ Iranian National Institute for Oceanography and Atmospheric Science, Tehran, Iran; vahid.chegini@gmail.com \\ ${ }^{3}$ University of Tehran, Tehran, Iran; masoud.sadri@ut.ac.ir \\ ${ }^{4}$ Iran University of Science \&Technology, Tehran, Iran; siadatmousavi@iust.ac.ir \\ ${ }^{5}$ Iranian National Institute for Oceanography and Atmospheric Science, Tehran, Iran; yari.sadegh@gmail.com
}

\section{ARTICLE INFO}

\section{Article History:}

Received: 18 jul. 2016

Accepted: 4 Jan. 2017

\section{Keywords:}

Hypersalinity

Inverse Estuary

Residence Time

Bushehr

Persian Gulf

\begin{abstract}
Spatial measurements of conductivity, temperature and depth were used to study salinity variations along the principal channels of the tidal hypersaline creek network in the vicinity of Bushehr Port, Persian Gulf during three 25tidal cycles in both warm and cold months.

Salinity variations and tidal fluctuations were out of phase throughout the short inverse estuary. The salinity values inside the creek were higher during the warm month (August 2014) than the corresponding values during the cold month (December 2014) due to the change in evaporation rates. The salinity values, also, were linearly increased longitudinally from the inlet to the head especially during warm season.

Observed evaporation rates in August and December periods and the corresponding salinity differences between hypersaline water of the creek and the incoming seawater were used to determine the Residence Time (RT).

The longitudinal variation of RT showed almost linear increase from the inlet to the head. The maximum temporal distribution of RT represented an increase from $\sim 10$ days in winter to $\sim 30$ days in summer due to the change in the longitudinal salinity gradient.
\end{abstract}

\section{Introduction}

Since a semi-enclosed estuarine system is restricted by land, the heat exchange with the earth in the system is higher than corresponding values in open sea environment during both cold and warm seasons. Also river water is usually colder than the ocean in winter. So the mixed water from theses riverine and oceanic sources inside a positive estuary is also cooler than the oceanic water during the cold season. Therefore, water temperature inside the estuary increases during a flood and the maximum temperature occurs at the high water level. The opposite is true during the summer: since offshore water is usually colder than the water inside the estuary, the water temperature decreases during a flood and the minimum temperature occurs at the high water level. Due to the aforementioned difference in temperature inside and outside the positive estuary, water temperature decreases during winter and increases in summer as one moves longitudinally upstream [8].
Salinity increases during flood and in contrast it decreases during ebb, in a positive estuary [8]. Salinity also decreases from the inlet to the head with approaching to fresh riverine water. A Gaussian distribution might be used to describe this longitudinal decrease:

$S(x)=35 \exp \left[-\frac{x^{2}}{2 \delta_{x}^{2}}\right]$

where $\boldsymbol{S}(\boldsymbol{x})$ is salinity in the sampling station with distance $\boldsymbol{x}$ from the inlet, $\mathbf{3 5}$ in the right hand side of Eq.(1) introduces seawater salinity whereas river inflow to the positive estuary is assumed to be fresh. $\boldsymbol{\delta}_{\mathbf{x}}$ is the dispersion coefficient of salinity [8].

As sea water resides inside a creek network, the salinity inside the creek might become higher than in the open sea due to evaporation. Such a creek system is similar to an inverse estuary because its density is much higher than that of the open sea especially in the summer time. This is in contrast with the classic (positive) estuaries where fresh water input decreases the water density inside the estuary ([27] and [24]). 
Compared to positive estuaries, one would expect that salinity shows the opposite trend in an inverse estuary, rising during ebb and falling during flood. Also as water resides inside an inverse estuary, evaporation increases the salinity longitudinally in an upstream direction.

The hypersaline structure along an inverse estuary indicates the time during which an oceanic water parcel resides in a shallow basin with a high rate of evaporation [13]. This time period for a water parcel is known as its "residence time" (hereafter denoted by RT). Similar definitions for RT of a water parcel are presented in the literature with emphasis on different aspects of an estuary ([2], [3], [5], [6], [14], [16], [20], [21], [25] and [28]).

Since inside a creek network, which is a hypersaline environment, salinity is always a significant dynamics indicator, in this study, RT is defined according to Largier et al. (1997) [13]. They determined RT in seasonal inverse estuaries using a Lagrangian salt balance equation presented as follows:

$R T($ in days $)=\frac{S-S_{i}}{S_{a v} \times \frac{E_{a v}}{D_{a v}}}$

where, $S_{i}$ is salinity at the inlet and $S$ represents salinity at any specific location. Also, $\boldsymbol{D}_{a v}, \boldsymbol{E}_{a v}$, and $\boldsymbol{S}_{\boldsymbol{a}}$ denote means of depth, evaporation rate, and salinity in the basin during RT, respectively [13].

In addition, Based on Hearn and Robson (2002) study [10], Mudge et al. (2008) suggested the following RT formula for the Ria Formosa Lagoon, using salinity tracing in June 2004 [15].

$R T$ (in days $)=\frac{s-S_{i}}{s_{i} \times P}$

where, the coefficient $\boldsymbol{P}$ represents the proportion of the water column evaporated per day. The mean evaporation rate $(5.4 \mathrm{~mm}$ day-1), determined from a commercial salt pond was converted to the $\boldsymbol{P}$ coefficient using depth data [15]. The average salinity value measured at the inlet for different readings during high water was used for $\boldsymbol{S}_{i}$. Comparison of Eq. (2) and Eq.(3) shows that $\boldsymbol{S}_{\boldsymbol{a} v}$ and $\boldsymbol{E}_{\boldsymbol{a}} / \boldsymbol{D}_{\boldsymbol{a}}$ in the denominator of Eq.(2) are replaced by $\boldsymbol{S}_{i}$ and $\boldsymbol{P}$ in Eq.(3) respectively.

Mudge et al. (2008) used $\boldsymbol{P}=0.0065 \mathrm{day}^{-1}$ which was much higher than the 0.001 day $^{-1}$ suggested by Hearn and Robson (2002) [15]. They argued that the water depth of their study area was often less than $5 \mathrm{~m}$, and a higher value of $\boldsymbol{P}$ was expected in a shallower study area. However, no constructive method was presented to determine $\boldsymbol{P}$ in the study of Mudge et al. (2008). In addition, they did not survey the seasonal variation of RT due to the changes in evaporation rate and salinity from the warm season to the cold season. So, in this study, Largier et al. (1997) formula is selected for calculating of RT.

The aim of this work is to explore and to describe the intra-tidal and longitudinal salinity variations inside the creek as a case of inverse estuarine systems. In addition to, seasonal and longitudinal variations in RT in the creek were determined using salinity tracing according to Largier et al. (1997) in both warm and cold seasons.

The port of Bushehr is located in the north end of a small peninsula on the northwestern coast of the Persian Gulf (See Figure 1). This peninsula is $14 \mathrm{Km}$ long, and the creek network and shallow waters of the Persian Gulf are located on its eastern and western neighbors, respectively. Large commercial vessels use the Bushehr Port through the studied creek. The navigation traffic at the port was on average 3910 vessel/year for the time period of 2009 to 2014. New phase of port development has been started recently due to its importance for Iran. However, little is known about the physical oceanography of the mentioned creek due to limited available physical data.

Moreover, RT is an important parameter at the creek network because it is extremely useful in determination of water contamination and nutrient levels, distributions of organisms, and their spatiotemporal variations in the system. Therefore, it is important to estimates residence times within this semi-enclosed basin during different months. The RT is commonly used in producing comparative assessments of how estuaries respond to human use. It is also used to understand and predict the effects of contaminants in estuarine systems and coastal waters [12]. There is an implication that RTs of water parcels are either closely linked to RTs of contaminations [26] or that at least highly correlated to RTs of contaminants ([4] and [7]). Applications of RT include determining the fate of hazardous waste spills, rates of accumulation of chemical contamination from chronic point and non-point sources in sediment, steady-state aqueous concentrations of nutrients, calculations of total maximum daily loads of municipal waste, and rates of export of fish eggs and larvae released within an estuarine system.

So far, the seasonal changes in RT have been rarely considered in inverse estuaries. In this study, the longitudinal variations in RT, and its seasonal changes in the short creek are determined using salinity data.

\section{Study Area}

The studied area is located at $28^{\circ} 55^{\prime} \mathrm{N}$ to $29^{\circ} 01^{\prime} \mathrm{N}$, and $50^{\circ} 49^{\prime} \mathrm{E}$ to $50^{\circ} 55^{\prime} \mathrm{E}$. This area, shown in Figure 1 , is a part of the Persian Gulf adjacent to Bushehr Port. It consists of a creek network, in which a main tidal channel, the Soltani creek (SC hereafter), is divided into the Poodar and Lashgari creeks (PC and LC hereafter, respectively). These two creeks extend to shallow branches where finally, the PC leads to intertidal flats and sparse mangrove in the border of Busher Port while LC ending at intertidal mudflats on 
the south coast of the Shif Island (see Figure 1). No freshwater input is available in this system. This area has a subtropical desert low-latitude arid hot climate (Köppen-Geiger classification: BWh). The annual mean air temperature in Bushehr port is $\sim 24^{\circ} \mathrm{C}$, and the annual precipitation is $228.5 \mathrm{~mm} /$ year [1]. The average annual relative humidity is $65 \%$ while the average monthly relative humidity varies from $56 \%$ in May to $75 \%$ in January [1].

In the studied area, the tide is mixed and mainly semidiurnal where the tidal range is often less than 2 $\mathrm{m}$ and it exceeds $2 \mathrm{~m}$ only during intense spring tide. A minimum depth of 7 meters are maintained by regular dredging in some part of Soltani, Lashgari and Poodar channels due to navigation requirements. The channel widths of these parts do not exceed $400 \mathrm{~m}$. The maximum depth of the creek network and its adjacent open waters is $14 \mathrm{~m}$. Tidal stirring is strong enough to make a well-mixed water column inside this shallow network.

The dominant wind is from the north-west and is locally entitled the "Shamal" wind [22]. Another important wind is southeasterly wind blowing in December. The wind is locally entitled the "Ghouse" wind and it is associeted with intense precipitations at Bushher. On the offshore side of the study area, the bottom slope is small and the $25 \mathrm{~m}$ isobath is located $15 \mathrm{~km}$ farther offshore from the coast.

Generally, the water column of the northern part of the Persian Gulf is vertically mixed during the winter due to wind and tidal stirring. The thermocline forms in May, and stratification separates the top $20 \mathrm{~m}$ from the bottom layer [17]. The water temperature difference between summer and winter reaches up to $20^{\circ} \mathrm{C}$ in the north-west of the Persian Gulf, much higher than the temperature difference close to the Strait of Hormuz $\left(11^{\circ} \mathrm{C}\right)$ at the eastern boundary of the Persian Gulf (see Figure 1).

Due to the high evaporation, salinity increases gradually from south to north. In the north-west of the Persian Gulf, the water salinity in winter is higher than in the beginning of summer [18]. Hydrographical data also confirm that during winter, the water density is higher in the north-west of the Persian Gulf than in the eastern part, and diffuses toward the Strait of Hormuz. The seasonal variations in sea level slope are consistent with the mentioned density driven circulation [11].

During winter, the northwesterly wind also weakens the oceanic currents entering the Persian Gulf along the Iranian coastline. These currents are stronger during the summer and reach the northern end of the Persian Gulf ([17] and [19]). 


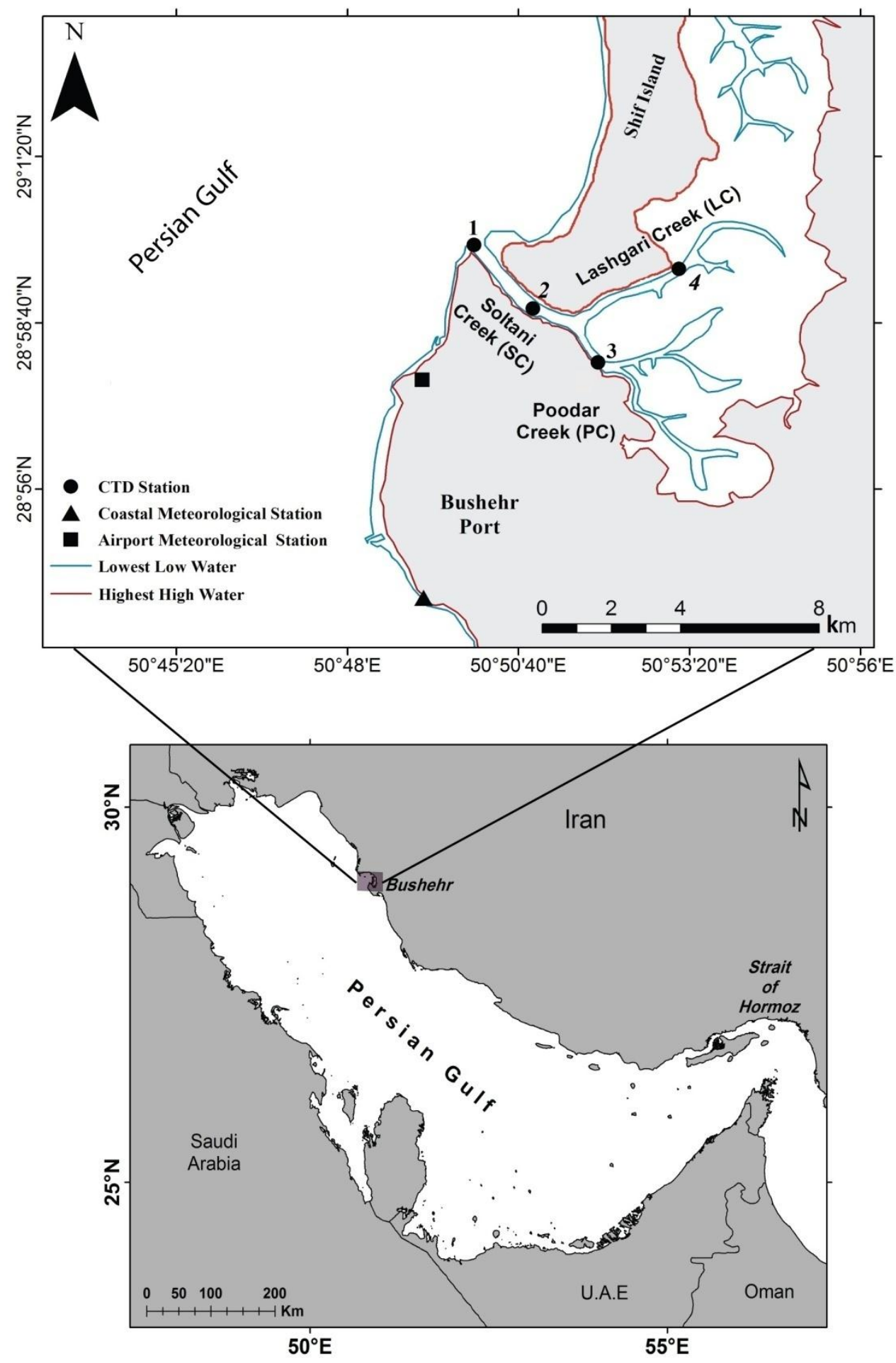

Figure 1- The study area and the locations of the CTD stations. The intertidal storage of the studied creek is the area between lowest low water (blue line) and highest high water (red line).

\section{Method}

In this study, four CTD-Current meters (RCM9 KMII; Aanderaa), located at Stations 1 to 4 in Figure 1 were deployed during three 25 -hour tidal cycles in the warm (August) and cold (December) months. These stations were selected at the creek inlet, SC, PC, and LC and the data recording were started from 18:25, 28 August 2014 to 21:25, 31 August 2014, and from 01:00, 26 December 2014 to 04:00, 29 December 2014. RCM9s were set to record data every $10 \mathrm{~min}$, and were fixed at $1 \mathrm{~m}$ from the bottom.
It should be noted that the current data measured by the RCM9s are not investigated in this study, and the time series of conductivity (C), temperature (T), and depth (D) are used to calculate salinity [23]. Also, there was no rainfall during the two measurement periods. In addition, the conductivity sensors malfunctioned at Station 4 in August as well as at Station 3 in December and recorded no reliable data. Instantaneous variations in salinity and water level were studied in two tidal cycles during the warm and cold months. The evaporation rates were available 
from two synoptic stations at Bushehr Airport and on the coast (see Figure 1). The distances between the airport and the coastal meteorological station and the studied creeks are $4 \mathrm{~km}$ and $8.5 \mathrm{~km}$, respectively. In these stations, evaporation was recorded at 6-UTC (it equals to 10:30 $\mathrm{AM}$ and 09:30 $\mathrm{AM}$ in local Iranian time during first and second six months of the year respectively) once a day. Evaporation from the free water surface using an American class A-Pan was measured at both stations. This pan was a cylinder 10 in $(25.4 \mathrm{~cm})$ high and 47.5 in $(120.65 \mathrm{~cm})$ diameter which filled up to $5 \mathrm{~cm}$ below its top (water depth=20.4 cm).

\section{Results and Discussion}

\subsection{Tidal Variations of Salinity and Temperature}

The time series of the salinity variations and tidal fluctuations at the inlet (Station 1) and two stations at the head of the creek (Station 3 in August and Station 4 in December) during one tidal cycle in the warm and cold months are presented in Figure 2. Each tidal cycle was specified between two consecutive co-phase low waters, denoted by L1 and L3 in Figure 2. They started at L1 and finished at L3 after passing through high water (H1), low water (L2) and the next high water $(\mathrm{H} 2)$. Figure 2 shows that salinity oscillates over a period similar to that for tidal fluctuation in both the warm and cold seasons, but with a phase difference of approximately 180 degrees. The phase difference was observed through the creek from the inlet to the head. The lower-saline waters from the sea flood into the creek, and the salinity decreases throughout the creek, and during the ebb tide the salinity rises as water resides inside the creek.
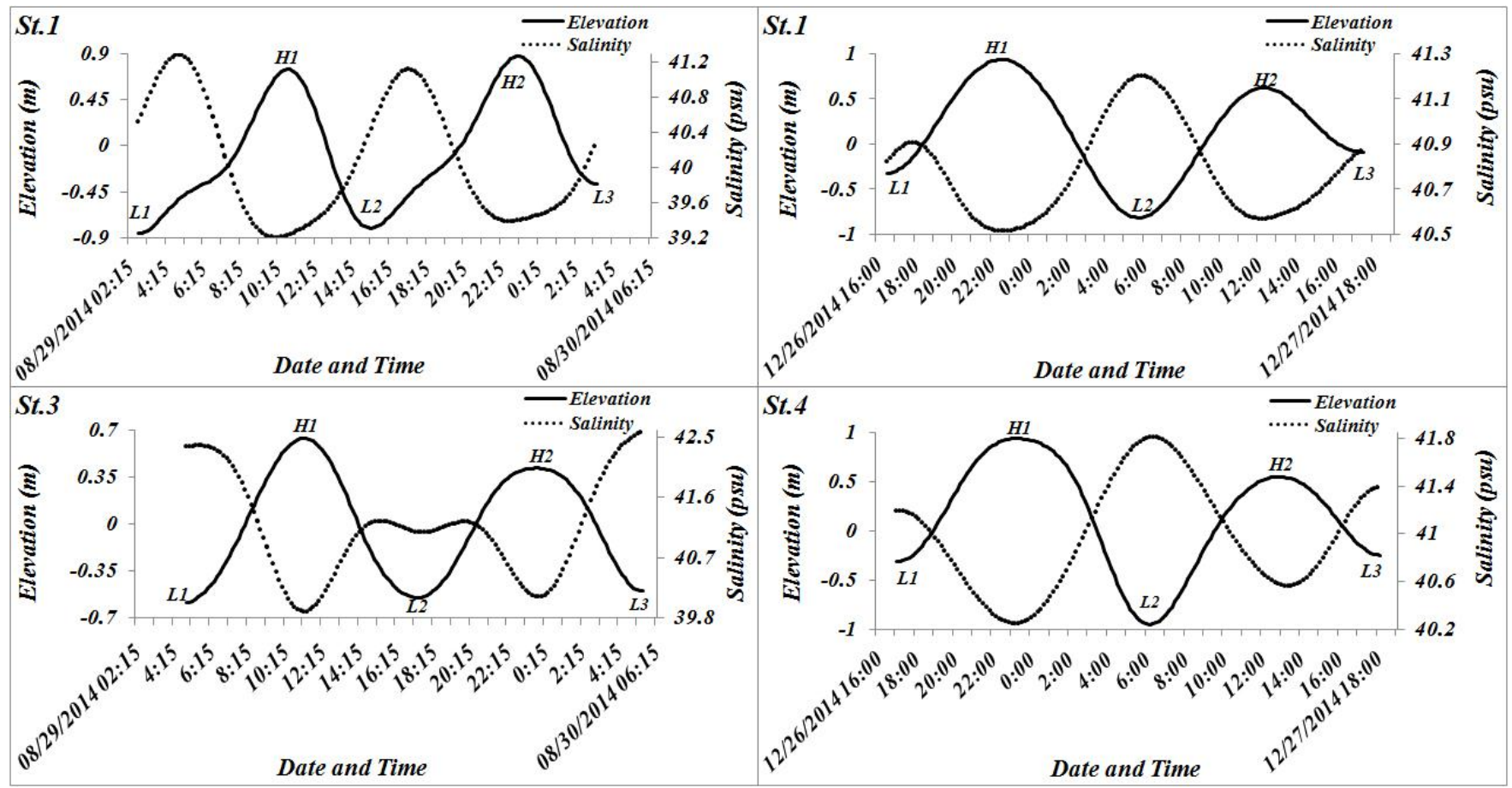

Figure 2. A typical tidal cycle of salinity and tidal fluctuations at different stations in August and December 2014.

The tidal scatter diagram of the recorded temperature and salinity at the inlet (Station 1) and upstream at Stations 3 and 4 in the cold and warm months (December and August 2014) are presented in Figure 3 for the time period between L1 and L3.

As shown in Figure 2, the time series of salinity was inversely correlated with the tidal fluctuations, and salinities in low waters (LWs) are higher than those of high waters (HWs). So it is in contrast with salinity variations in positve estuaries where HWs have higher salinities than LWs.

The irregular $\mathrm{T}-\mathrm{S}$ scatter was resulted from irregular temperature variations during the tidal cycle inside the creek. However, the T-S diagram, especially at the inlet (Station 1), shows that the water temperature was correlated to the water level fluctuations in August, and inversely correlated to the water level fluctuations in December. This is due to the fact that the creek waters were warmer than the offshore sea temperature in summer. During winter, waters within the creek were colder than the open sea waters. Therefore, the temperature inside the creek increases during the ebb in summer whereas in winter the water temperature increases during flood. 


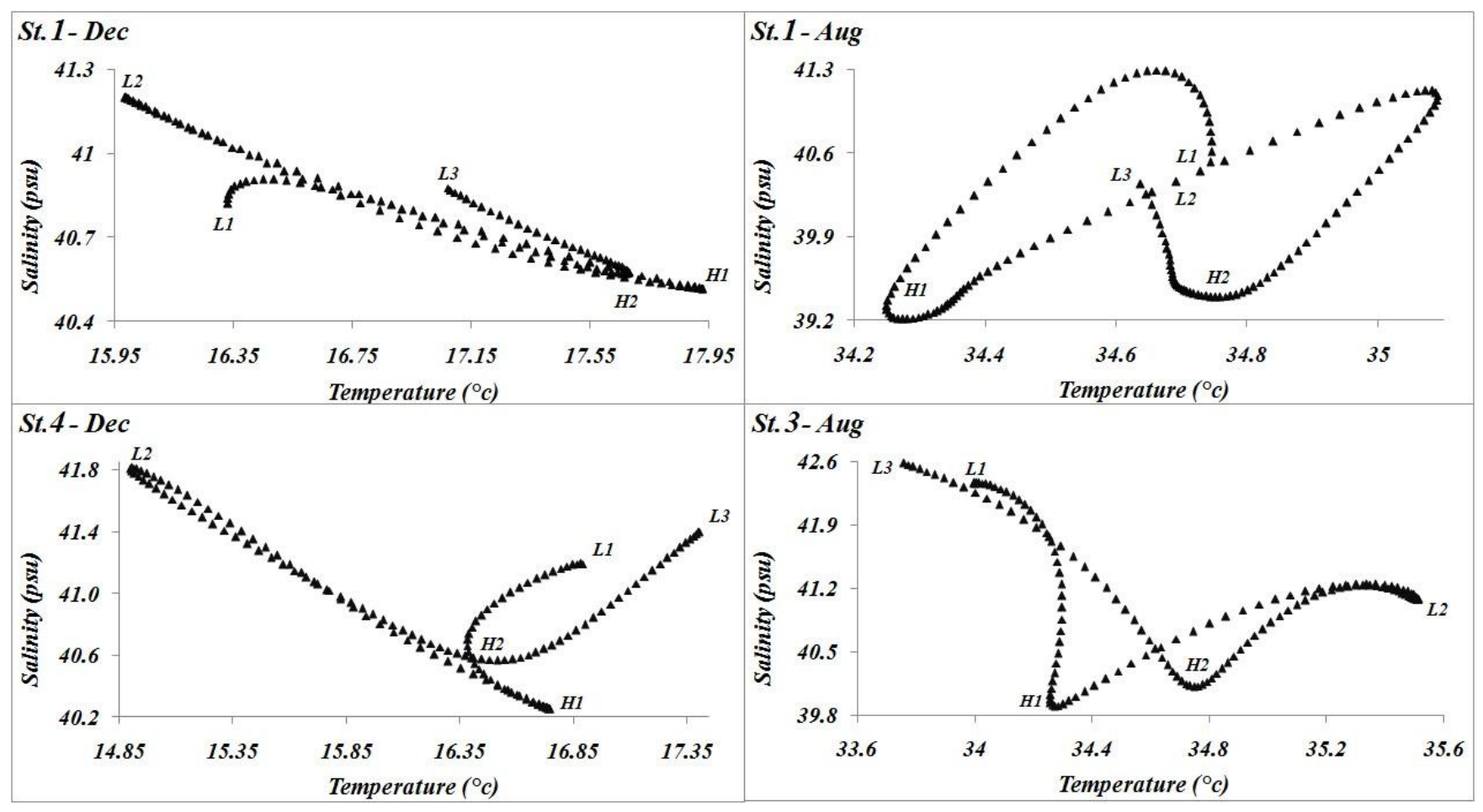

Figure 3. T-S scatter plot during one tidal cycle at different stations in August and December 2014.

\subsection{Longitudinal Variations of Salinity}

The tidally-averaged values of the time series of water temperature and salinity during three full tidal cycles in August and December 2014 at the inlet and inside the creek are presented in Table 1. During both warm and cold months, salinity increases from the inlet to the head. At the inlet and SC (Stations 1 and 2), the average salinity in the cold month were higher than the corresponding value in the warm month as they were affected by the open water salinity variations of the Persian Gulf in which the salinity is higher during the winter than during the summer ([17], [18] and [19]).

The growth in longitudinal salinity gradient in the summer time is due to the higher evaporation in summer than in winter. Generally, salinity is homogeneous in the vertical profile of a well-mixed estuary.

During both the warm and cold months, the deepest RCM9 (Station 4) recorded the lowest temperature. Also, the mean water temperature inside the creek is colder than that of the inlet water in winter and warmer than that of the inlet water in summer.

The following distribution could be proposed to describe the longitudinal variations of salinity for this creek.
$S(x)=S_{i} \exp \left(\frac{x^{2}}{2 \delta_{x}^{2}}\right)$

Compared to Eq.(1), the value of 35 was replaced with the inlet salinity. Also, the negative sign was removed in the exponential term so that salinity would increase from the inlet $(\mathrm{x}=0)$ to the seawater intrusion length $\left(\boldsymbol{x}_{\max }\right)$. The distances of Stations 2, 3, and 4 from Station 1 at the inlet are 2855, 5300, and $7100 \mathrm{~m}$ respectively.

If the above formula is applied to salinity data in August and December, the salinity dispersion coefficients $\left(\boldsymbol{\delta}_{\boldsymbol{x}}\right)$ respectively equal 21.98 and 71.59 $\mathrm{km}$, from the regression analysis. The root mean square errors of the estimated salinity values at those three stations using these salinity dispersion coefficients were 0.175 PSU in August and 0.030 PSU in December.

Assuming a linear regression curve would result in gradients of 0.195 and $0.025 \mathrm{PSU} / \mathrm{km}$ in the warm and cold months respectively. The root mean square errors of the estimated salinities using the linear regression line would be 0.021 PSU in August and 0.004 PSU in December. Therefore, a linear longitudinal salinity distribution is more appropriate than the exponential distribution for this short hypersaline creek.

Table 1. Tidal mean temperature and salinity at different stationsin August and December 2014.

\begin{tabular}{ccccccccc}
\hline Time Duration & \multicolumn{4}{c}{75 hours in August 2014 } & \multicolumn{4}{c}{75 hours in December 2014 } \\
\hline Station & 1 & 2 & 3 & 4 & 1 & 2 & 3 & 4 \\
& $($ Inlet $)$ & $(\mathrm{SC})$ & $(\mathrm{PC})$ & $(\mathrm{LC})$ & $($ Inlet $)$ & $(\mathrm{SC})$ & $(\mathrm{PC})$ & $(\mathrm{LC})$ \\
\hline Temperature $\left({ }^{\circ} \mathrm{c}\right)$ & 34.72 & 34.91 & 34.77 & 34.59 & 17.14 & 16.78 & 16.49 & 16.32 \\
\hline Salinity $(\mathrm{psu})$ & 40.15 & 40.75 & 41.18 & ---- & 40.82 & 40.90 & ----- & 41.00 \\
\hline
\end{tabular}




\subsection{RT using Salinity}

In order to apply the Eq.(2) [13], the salinity at Station 1 presented in Table 1 was selected as $\boldsymbol{S}_{i}$. The salinity values at Stations 2, 3 and 4 were also used to determine the RT. Moreover, the average of the daily evaporation rates was determined using data from two Bushehr meteorological stations in the CTDmeasurement durations from 28 August 2014 to 31 August 2014, and from 26 December 2014 to 29 December 2014. The values of 5.10 and $2.73 \mathrm{~mm} /$ day, were used as the $\boldsymbol{E}_{a v}$ for the August and December periods respectively. Using bathymetry data, $\boldsymbol{D}_{a v}$ was selected as $5.66 \mathrm{~m}$ based on averaging more than 1400 depth data located between Stations 1, 3 and 4 varying from 0.1 to $14.1 \mathrm{~m}$. Also, the average salinity of the creek network $\left(\boldsymbol{S}_{\boldsymbol{a v}}\right)$ was estimated by averaging the salinity values from Stations 1, 2 and 3 in August and Stations 1, 2 and 4 in December. The final results for $\mathrm{RT}$ are presented in Table 2.

Table 2. RT in the creek based on Largier et al., (1997) formula [13], in the creek.

\begin{tabular}{ccccc}
\hline Time & \multicolumn{2}{c}{ August 2014} & \multicolumn{2}{c}{ December 2014} \\
\hline Station & St.2 & St.3 & St.2 & St.4 \\
\hline $\begin{array}{c}\text { RT } \\
\text { (days) }\end{array}$ & 16.51 & 28.17 & 4.00 & 9.15 \\
\hline
\end{tabular}

According to Eq.(2), RT increases with the increase in longitudinal salinity difference and average depth, while it decreases with increases in salinity and evaporation means. Note that, close to the Bushehr, the MSL increases by approximately $20 \mathrm{~cm}$ in summer compared to winter [9]. Therefore, a change in $\boldsymbol{D}_{\boldsymbol{a}}$ has a negligible effect on RT variation throughout the year. Similarly, the variation in $S_{a v}$, from winter to summer is insignificant compared to variations in evaporation rate and salinity gradient.

In a hypersaline creek network, increasing the evaporation rate from winter to summer results in an increase in the axial salinity difference $\left(\boldsymbol{S}-\boldsymbol{S}_{\boldsymbol{i}}\right)$. The evaporation rate in August was almost twice that of the corresponding value in December. The salinity difference between the inlet and the stations inside the creek was more than five fold larger in August than in December. Since the increase inevaporation rate is smaller than the rise in salinity gradient, RT is mainly affected by the salinity gradient. As a result, RT is lower in the cold months than in the warm months.

The rates of longitudinal changes of RT is 5.3 day $/ \mathrm{km}$ at Station 3 in August and 1.3 day $/ \mathrm{km}$ at Station 4 in December. If these rates are applied to Station 2, RTs at Station 2 would be 15.2, and 3.7 days in the warm and cold months respectively, which differs almost 1 day from the RTs calculated by Largier's formula (see Table 2). Therefore, RT shows linear distribution as a result of the linear change in salinity inside the short creek. This is in accordance with the conclusion of Largier et al. (1997), which states that, if the rate of water exchange and depth remains constant, the salinity and RT increase linearly from the inlet to the head [13].

\section{Conclusions}

In this study, tidal variations of salinity and temperature were surveyed in a hypersaline creek network close to Bushehr Port, Iran during two warm and cold months.

The results showed this creek behaves similarly to the shallow and short inverse estuary, and the $\mathrm{T}-\mathrm{S}$ diagrams during the tidal cycles indicate that hypersalinity varies throughout the tidal cycle, and weakens during flood and reinforces during ebb in both warm and cold seasons. The phase difference between salinity and tidal fluctuations was approximately 180 degrees throughout the creek. The water temperature inside the creek decreases during ebb and reaches its minimum value at low water in winter because the water inside the creek is colder than the adjacent open seawater.

In summer, water temperature inside the creek is generally warmer than the sea water; therefore, the water temperature from in situ observation, especially in the creek inlet, increases during ebb and reaches its maximum value at low water. The mean temperatures inside the creek were colder than the temperatures in the inlet in winter, and the opposite was true in summer. Measurements also showed that salinity linearly increases longitudinally from the inlet to the head.

Finally, the RT of a water parcel was calculated using the formula suggested by Largier et al. (1997) [13]. Longitudinal variations of RT showed that it increased linearly from the inlet towards the estuary head. The RT inside the estuary was much longer in the summer than in the winter.

\section{Acknowledgment}

This work was supported by the Iranian National Institute for Oceanography and Atmospheric Science (INIOAS) at the Persian Gulf Centre for Oceanography. The authors gratefully acknowledge the Applied Meteorology Research Center of Bushehr (AMRCB) to provide the meteorological data.

\section{References}

1- Applied Meteorological Research Center of Bushehr, AMRCB, (2015), Statistical observations of atmospheric parameters of the Bushehr meteorological station, 2015 Technical Report.

2- Blaise, S., De Brye, B., De Brauwere, A., Deleersnijder, E., Delhez, E.J. and Comblen, R., (2010), Capturing the residence time boundary layerapplication to the Scheldt Estuary, Ocean Dynamics, Vol.60(3), p.535-554. 
3- Bolin, B. and Rodhe, H., (1973), A note on the concepts of age distribution and transit time in natural reservoirs, Tellus, Vol.25(1), p.58-62.

4- Choukroun, S., Ridd, P.V., Brinkman, R. and McKinna, L.I., (2010), On the surface circulation in the western Coral Sea and residence times in the Great Barrier Reef, Journal of Geophysical Research: Oceans, 115(C6).

5- Delhez, É.J., Heemink, A.W. and Deleersnijder, É., (2004), Residence time in a semi-enclosed domain from the solution of an adjoint problem, Estuarine, Coastal and Shelf Science, Vol.61(4), p.691-702.

6- Dronkers, J. and Zimmerman, J., (1982), Some principles of mixing in tidal lagoons, Oceanologica Acta, Special issue.

7- Hancock, G.J., Webster, I. and Stieglitz, T.C., (2006), Horizontal mixing of Great Barrier Reef waters: Offshore diffusivity determined from radium isotope distribution, Journal of Geophysical Research: Oceans, 111(C12).

8- Hardisty, J., (2008), Estuaries: monitoring and modeling the physical system, John Wiley \& Sons.

9- Hassanzadeh, S., Kiasatpour, A. and Hosseinibalam, F., (2007), Sea-level response to atmospheric forcing along the north coast of Persian Gulf, Meteorology and Atmospheric Physics, Vol.95(3), p.223-237.

10- Hearn, C.J. and Robson, B.J., (2002), On the effects of wind and tides on the hydrodynamics of a shallow Mediterranean estuary, Continental Shelf Research, Vol.22(18), p.2655-2672.

11- Hosseinibalam, F., Hassanzadeh, S. and Kiasatpour, A., (2007), Interannual variability and seasonal contribution of thermal expansion to sea level in the Persian Gulf, Deep Sea Research Part I: Oceanographic Research Papers, Vol.54(9), p.14741485.

12- Jickells, T., (1998), Nutrient biogeochemistry of the coastal zone, Science, Vol.281(5374), p.217-222.

13- Largier, J., Hollibaugh, J.T. and Smith, S., (1997),

Seasonally hypersaline estuaries in Mediterraneanclimate regions, Estuarine, Coastal and Shelf Science, Vol.45(6), p.789-797.

14- Meyers, S.D. and Luther, M.E., (2008), A numerical simulation of residual circulation in Tampa Bay. Part II: Lagrangian residence time, Estuaries and Coasts, Vol.31(5), p.815-827.

15- Mudge, S.M., Icely, J.D. and Newton, A., (2008), Residence times in a hypersaline lagoon: using salinity as a tracer, Estuarine, Coastal and Shelf Science, Vol.77(2), p.278-284.
16- Prandle, D., (1984), A Modelling Study of the Mixing of $\$^{\wedge}\{137\} \$$ Cs in the Seas of the European, Continental Shelf Philosophical Transactions of the Royal Society of London A: Mathematical, Physical and Engineering Sciences, Vol.310(1513), p.407-436.

17- Reynolds, R.M., (1993), Physical oceanography of the Gulf, Strait of Hormuz, and the Gulf of Oman-Results from the Mt Mitchell expedition, Marine Pollution Bulletin, Vol.27, p.35-59.

18- ROPME, (2003), State of the marine environment report 2003, ROPME/GC-11/003, Kuwait.

19- Sadrinasab, M. and Kämpf, J., (2004), Three dimensional flushing times of the Persian Gulf, Geophysical research letters, 31(24).

20- Takeoka, H., (1984), Fundamental concepts of exchange and transport time scales in a coastal sea, Continental Shelf Research, Vol.3(3), p.311-326.

21- Tartinville, B., Deleersnijder, E. and Rancher, J., (1997), The water residence time in the Mururoa atoll lagoon: sensitivity analysis of a three-dimensional model, Coral Reefs, Vol.16(3), p.193-203.

22- Thoppil, P.G. and Hogan, P.J., (2010), Persian Gulf response to a wintertime shamal wind event, Deep Sea Research Part I: Oceanographic Research Papers, Vol.57(8), p.946-955.

23- UNESCO, (1981), Report No. 37. Practical Salinity Scale 1978: E.L. Lewis, IEEE Ocean Engineering, Jan., 1980. 145pp.

24- Valle-Levinson, A., (2010), Definition and classification of estuaries, In: A. Valle-Levinson, (ed.), Contemporary Issues in Estuarine Physics, Cambridge University Press, p.1-11.

25- van de Kreeke, J., (1983), Residence time: application to small boat basins, Journal of waterway, port, coastal, and ocean engineering, Vol.109(4), p.416-428.

26- Wang, Y., Ridd, P.V., Heron, M.L., Stieglitz, T.C. and Orpin, A.R., (2007), Flushing time of solutes and pollutants in the central Great Barrier Reef lagoon, Australia Marine and Freshwater Research, Vol.58(8), p.778-791.

27- Winant, C.D. and Gutiérrez de Velasco, G., (2003), Tidal dynamics and residual circulation in a well-mixed inverse estuary, Journal of Physical Oceanography, Vol.33(7), p.1365-1379.

28- Zimmerman, J.T.F., (1988), Estuarine residence times, In: Kjerfve, B. (Ed.), Hydrodynamics of Estuaries, vol.1, CRC Press, p.75-84. 